\title{
Surveying the Damage: A Review of Research on Consequences of Alcohol Misuse in College Populations
}

\author{
H. WESLEY PERKINS, PH.D. ${ }^{\dagger}$ \\ Department of Anthropology and Sociology, Hobart and William Smith Colleges, Geneva, New York 14456
}

\begin{abstract}
This article provides a review and synthesis of professional research literature on the types, extent and patterns of negative consequences produced by students' misuse of alcohol in college populations based on survey research conducted during the last two decades. Considerable evidence is available documenting a wide range of damage by some students' drinking done to themselves as well as to other individuals, although some types of consequences remain speculative. Damage and costs to institutions are likely to be substantial, but this claim remains largely an inference based on current studies. Drinking by males compared with that of females produces more consequences
\end{abstract}

for self and others that involve public deviance, whereas females' drinking contributes equally with males to consequences that are personal and relatively private. Research on racial/ethnic background, time trends and developmental stages reveals patterns in student data on consequences of drinking, but these data are very limited in the literature. Evidence suggests there is only a modest correlation between students' self-perception of having a drinking problem and the many negative consequences of drinking that are reported. (J.Stud. Alcohol, Supplement No. 14: 91-100, 2002)

\begin{abstract}
A LCOHOL IS routinely cited by researchers, college administrators and staff, and also by students themselves, as the most pervasively misused substance on college campuses. Anecdotal evidence and dramatic examples of negative consequences of college student drinking are readily found in counseling and hospital records and police reports as well as in the simple observation of property damage and litter following many campus social events. Questions remain, however, about the actual patterns and pervasiveness of student alcohol misuse. What is the range and extent of negative consequences found in student populations? Are problems broadly experienced or are they concentrated primarily in certain individuals who tend to suffer many consequences, and what are the consequences for academic institutions? This article provides a review and synthesis of the existing professional research literature addressing these questions about the types and extent of negative consequences, what can be concluded about their distribution from consistent findings, what is more speculative based on limited research and what is still unknown due to the lack of research. A review of all the causal factors contributing to drinking problems on college campuses, however, is a task beyond the scope of this article.

This review of damage due to collegiate alcohol misuse draws most evidence from anonymous student surveys conducted and published within the last two decades. Some studies have collected large nationwide databases, thus
\end{abstract}

\footnotetext{
†The author may be reached at the above address or via email at: perkins@hws.edu.
}

providing the greatest generalizability. Studies based on data collected at individual colleges and universities are also included, demonstrating variation and similarity in certain types of consequences across regions and institutional contexts. Studies of single institutions also provide assessments of additional consequences or different measures of consequences that broaden the assessment of damage. Both the national and local studies report the prevalence of problems at varying historical moments and with measures spanning a variety of time frames (e.g., within the last week, within the academic year or over one's lifetime).

Finally, it is important to note that some studies provide prevalence rates among the entire student population whereas other studies report the prevalence of consequences only among drinkers. Both rates provide important information about negative consequences. The former provides a general measure of pervasiveness and the latter a risk measure indicating how likely it is that a student's drinking is going to result in a particular type of problem. Thus, where possible, based on the data provided in the published study, rates for drinkers are calculated and included in this review along with published rates of the entire student sample. Likewise, rates for the entire sample are calculated and included here along with published rates for drinkers only.

\section{Types of Consequences}

In surveying the collegiate damage that may accumulate from student alcohol misuse, it is useful first to divide the broad terrain of problems into categories depending on the 
object (self, others, institutions) and nature of the consequences. Table 1 presents the different foci used in cataloging the range of consequences in the college environment.

\section{Damage to self}

Risky drinking behavior may be the cause or important contributing factor in many different academic, emotional, physical, social and legal problems experienced by undergraduates. Indeed, the picture of extensive harm to at least a significant minority of students on most campuses is clearly supported by the research.

Academic impairment. A substantial amount of empirical research is available demonstrating a connection between alcohol consumption and impaired academic performance. Among 41,581 students responding to the Core Alcohol and Drug Survey in representative mail and classroom administrations at 89 institutions holding FIPSE drug prevention program grants nationwide in $1992-94,22 \%$ indicated that they had performed poorly on a test or project ( $26 \%$ of drinkers), and $28 \%$ had missed a class during the last year (33\% or one-third of drinkers) due to alcohol or other drug use (Presley et al., 1996). Wechsler et al.'s (1998) nationwide College Alcohol Study surveyed a nationally representative sample of 14,521 students attending 116 fouryear colleges and universities in 1997 and found that $24 \%$ (30\% of drinkers) reported missing a class within the current academic year as a result of drinking and 19\% (23\% of drinkers) reported getting behind in schoolwork during the current year as a result of drinking. Males drinking 5+ drinks or females drinking $4+$ drinks in a row one or two times in a 2 -week period were more than three times as likely to report getting behind in schoolwork due to their

TABLE 1. Potential negative consequences of college student drinking

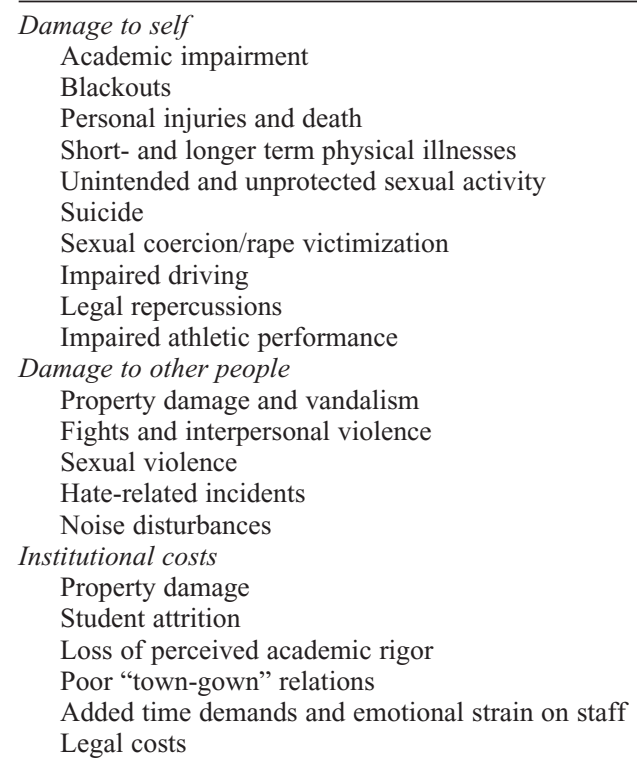

Legal costs

drinking in the current year in comparison with more moderate drinkers, and males drinking $5+$ or females drinking $4+$ drinks in a row on at least three occasions in a 2-week period were more than eight times more likely to report this problem.

Similarly, Engs et al.'s (1996) Student Alcohol Questionnaire administered to 12,081 students who were contacted in a demographically representative quota sample of 168 four-year institutions across the United States in 1994 revealed higher levels of consumption associated with markedly higher rates of alcohol-related academic problems. Among "low-risk drinkers" (males consuming 21 or fewer drinks and females consuming 14 or fewer drinks per week), $11 \%$ had missed class due to a hangover, and less than $3 \%$ noted having received a lower grade due to drinking. Among "high-risk" drinkers $(22+$ drinks/week for males and 15+ drinks/week for females), however, more than half of these survey respondents had missed classes due to a hangover, and more than $15 \%$ reported receiving a lower grade due to their drinking.

High rates of drinking-related academic problems can be found in demographically diverse campus settings. For example, Werch et al. (1987) found that $18 \%$ of a sample of 410 students ( $23 \%$ of drinkers in the sample) attending a midsize southern university admitted they had missed class due to a hangover in the past year. Perkins (1992) found one-third of students reporting they had missed classes or examinations or had performed poorly on assignments due to their drinking during the academic year in a sample of 584 students from a small, private college with few abstainers in the Northeast.

In addition to students' subjective determinations of academic impairment, a consistent association between selfreported grade averages and levels of alcohol consumption is revealed in several studies. For example, among Core Survey respondents nationally (Presley et al., 1996), A average students consumed an average of 3.4 drinks per week, B average students were drinking 4.5 drinks, C students were drinking 6.1 drinks, and $\mathrm{D}$ or $\mathrm{F}$ students typically drank 9.8 drinks. This pattern was found at 2-year schools as well as 4-year institutions. Likewise, Engs et al. (1996) reported a consistent inverse relationship between weekly drink averages and grade point average in their national study. Of course, correlation does not prove causality here. Although quite plausible, it cannot be determined with certainty from these cross-sectional data that heavier drinking per se was responsible for the lower grade performances. Wood et al. (1997) provided this caution based on their study of 444 students attending a large midwestern university. Although they also found a bivariate association between problematic alcohol use and academic problems, most of the association was accounted for by controlling for family background factors and student academic characteristics that existed before any collegiate drinking. 
Blackouts. The phenomenon of alcohol-induced "blackouts" or memory loss during periods of heavy drinking is a common consequence found among alcoholics but has also been found in other populations of drinkers as well. It is not always clear whether such reports include partial forgetting, or perhaps mistaking blackout if undefined as passing out (Buelow and Koeppel, 1995). Nevertheless, in the nationwide College Alcohol Survey (Wechsler et al., 1998), $22 \%$ of students $(27 \%$ of drinkers) reported at least one incident of having forgotten where they were or what they did due to drinking in the past year. Similarly, $26 \%$ of respondents ( $31 \%$ of respondents who drank) in the Core Survey indicated that they had "had a memory loss" due to drinking or other drug use in the past year (Presley et al., 1996). Upward to almost half of all students in several studies of regionally diverse single institutions reported having had such experiences within their lifetime (Buelow and Koppel, 1995; Sarvela et al., 1988; Werner et al., 1993). Meilman et al. (1990) found 4.4\% of students reporting a blackout within the last week in a random sample attending a private university in rural New England.

Personal injuries. Injuries to oneself as a result of one's drinking are not an uncommon consequence. The College Alcohol Study found $9 \%$ of students (12\% of drinkers) in this category within a 1-year period nationwide (Wechsler et al., 1998), and the Core Survey (Presley et al., 1996) revealed $13 \%$ ( $15 \%$ of drinkers) reporting injury to self as a consequence of alcohol or other drug use within the year. Perkins (1992) found one of five students having experienced this consequence within the academic year at a private northeastern college where more than $95 \%$ of students drank alcohol.

Physical illnesses. Short-term health-related consequences of heavy drinking such as hangovers, nausea and vomiting are experienced by a large minority, if not the majority, of students on most campuses. The Core Survey of students at 89 schools across the nation produced a self-report result of $40 \%$ with at least one hangover ( $47 \%$ of drinkers) and $47 \%$ (56\% of drinkers) having nausea or vomiting as a result of alcohol or other drug use within the year (Presley et al., 1996). In one study at a New England university where almost all students (97\%) drank alcohol within the year, however, $29 \%$ of the student sample reported that anywhere from .5 to 24 hours of their normal functioning were lost "in recovery" from drinking in the last week (Meilman et al., 1990). Alcohol poisoning as a result of excessive consumption and occasional fatalities that result from these extremely high blood alcohol levels are not unfamiliar incidents in campus health centers and local hospital emergency rooms. However, evidence of these tragic consequences is found only in news headlines and anecdotal reports. Systematically collected data on the prevalence of student alcohol poisoning are not available in the research literature.
Longer term consequences of heavy alcohol use to one's health may include reduced resistance to illnesses. Selfreported illnesses were correlated with drinks consumed per week among undergraduates enrolled in a general education course at a large midwestern university (Engs and AldoBenson, 1995). Although light to moderate consumption was not significantly associated with increased health risks, consuming an average of 22 drinks or more per week was associated with increased upper respiratory infections, and consuming 28 drinks or more was associated with greater acute illness on an aggregate measure, thus suggesting that heavy alcohol consumption contributes to lowered resistance to common illnesses among students. Of course, social background correlates of health care and drinking behavior may contribute to this association.

Unintended and unprotected sexual activity. In recent years, research has considered the potentially increased risk of engaging in sexual activity unintentionally as well as the increased risk of not using protection against pregnancy or sexually transmitted diseases. A variety of measures assessing the incidence of these different but related consequences (unintended and unprotected sexual relations) have been employed in student surveys. At a college in New York, Perkins (1992) found that one-quarter of the students reported engaging in either unintended or unprotected sexual activity at least once as a result of drinking during the academic year, with $15 \%$ of males and $10 \%$ of females reporting multiple occurrences. Wechsler and Isaac (1992) found that heavy episodic drinkers in Massachusetts colleges were about three times as likely as other drinkers to engage in unplanned sexual activity. Meilman (1993) found that one in five undergraduates at a southeastern college acknowledged having participated in sexual intercourse as a result of being under the influence of alcohol since coming to college, and $17 \%$ of undergraduates had abandoned safesex techniques under the influence of alcohol $(9 \%$ had done so on more than one occasion). In the 1997 College Alcohol Survey (Wechsler et al., 1998), 18\% of this sample ( $23 \%$ of drinkers) had engaged in unplanned sexual activity during the academic year, and $9 \%$ (11\% of drinkers) reported not using protection due to their drinking.

Among students sampled at 12 universities across the United States, Anderson and Mathieu (1996) found that, of those who had one or more sexual partners in the last year, $33 \%$ of the men and $17 \%$ of the women had let themselves drink "more than normal" at least once as a disinhibitor to make sex easier. In those circumstances, one-quarter of the sample did not initiate condom use. In another study, using a convenience sample of 210 participants from a large southeastern university, more than one-third of respondents reported drinking to enhance sexual experiences, and twothirds noted that their drinking had at some time had a negative consequence for them sexually (Poulson et al., 1998). In the same study, $70 \%$ of all students reported that 
they were less likely to use a condom in sexual activity after they had been drinking. Research at another southeastern university showed that for both men and women the frequency and quantity of usual alcohol consumption as well as having consumed alcohol prior to the last occurrence of sexual activity were positively associated with having multiple sexual partners (Desiderato and Crawford, 1995). Condom use did not demonstrate a consistent pattern in relation to alcohol use, however, in this research.

Suicide. Although links between suicide and substance abuse can be found in the research and clinical literature of psychopathologies, there are very little empirical data to draw on from the studies of broad college populations. Although most reports are anecdotal, some systematic survey evidence of the potential for alcohol misuse to result in this extreme consequence is suggested by national Core Survey data (Presley et al., 1996). Specifically, 5.1\% of respondents $(6.1 \%$ of drinkers) confided that they had suicidal thoughts, and $1.6 \%$ (1.9\% of drinkers) revealed that they had actually tried to commit suicide within the last year due to drinking or other drug use. It must be noted, of course, that the measure used is a self-perceived assessment of the causal order. It is certainly plausible that suicidal thoughts may lead to elevated drinking, as depression increases the propensity to drink heavily.

Sexual coercion and acquaintance rape victimization. The prevalence of sexual coercion and rape victimization among female undergraduates has received significant documentation in empirical research (see Koss et al., 1987). Much of this victimization experience has been linked to the victim's alcohol use (as well as to the perpetrator's consumption). Of those participating in the Core Survey nationwide (Presley et al., 1996), 12\% of females (14\% of female drinkers) reported having been taken advantage of sexually during the last year as a result of their drinking or other drug use. It is surprising to note that $11 \%$ of males ( $13 \%$ of male drinkers) also indicated this experience, given that most of the research has focused on female victimization.

Frintner and Rubinson (1993) found that 27\% of a random sample of female undergraduates at a midwestern university were victims of sexual assault, attempted sexual assault, sexual abuse or at least one incidence of battery, intimidation or illegal restraint. Of women who were victims, 55\% had been drinking at the time. Among drinking women who had experienced sexual assault or attempted sexual assault, $60 \%$ reported their judgment had been moderately or severely impaired at the time due to drinking. Similarly, Harrington and Leitenberg's (1994) research on 1,090 female undergraduates attending four New England universities revealed that $25 \%$ had been victims of sexual aggression by an acquaintance since age 16 and more than half of the victims were at least somewhat drunk when victimized. In a study of 1,025 single white female stu- dents between the ages of 17 and 23 at another large midwestern university, higher scores on a global measure of experiencing sexually coercive behaviors were linked to heavy drinking (Gross and Billingham, 1998).

Explanations for the association between female students' drinking and increased risk of sexual victimization most often point to (1) increased consensual sexual activity prior to the forced activity, as alcohol contributes to more casual sexual behavior that may be misinterpreted by the male as an invitation to further sexual contact; (2) the cultural stereotype of a drinking woman as "loose" and therefore more desirous of sexual contact; (3) the victim's diminished ability to communicate clearly her choice to reject sexual advances when she is intoxicated; and (4) the diminished ability of the victim to defend herself physically or flee from an aggressor. (Abbey and colleagues [Abbey, 1991; Abbey et al., 1996] provide a more in-depth review and theoretical analysis.) These explanations should not be interpreted as "blaming the victim." Rather, the point here as in the studies cited is that, regardless of the fact that the woman should always have the right to reject or limit sexual advances at any point in any intimate encounter, increased alcohol consumption substantially reduces her ability to avoid being victimized.

Impaired driving. For students who have access to cars, impaired driving performance may be another negative consequence of their collegiate drinking. National survey data reveal approximately one-third driving under the influence of alcohol during the academic year (Presley et al., 1996; Wechsler et al., 1998). According to Engs et al. (1996), $17 \%$ of males and $10 \%$ of females who were light-tomoderate weekly drinkers reported having driven while drunk at least once during the year, whereas $56 \%$ of males and $43 \%$ of females who were relatively heavy weekly drinkers reported having done so.

Legal repercussions. Alcohol misuse occasionally results in disciplinary action against students or in arrests and prosecutions for violation of liquor laws such as minimum age requirements, open container restrictions, public intoxication or driving while alcohol impaired. In nationwide survey data, findings range from $5 \%$ to $12 \%$ of students admitting trouble with police or campus authorities as a result of their alcohol use (Engs and Hanson, 1994; Presley et al., 1996; Wechsler et al., 1998). Student arrests for driving while intoxicated were reported at a rate of $1.7 \%(2.0 \%$ of all drinkers) in the Core Survey (Presley et al., 1996).

Impaired athletic performance. Many other personal consequences appear likely due to misuse of alcohol by various types of students, but systematic empirical research is lacking. Using national Core Survey data, Leichliter et al. (1998) have shown that athletic team members and, even more so, team leaders consume more alcohol per week than nonathletes. These athletes were more likely to consume in a heavy episodic fashion and generally incurred more nega- 
tive consequences as a result. There are no data in the research literature on student athletes, however, that specifically assess impaired athletic performance due to their drinking. It can only be inferred that there is significant performance loss, given relatively high consumption levels each week by some athletes that could be detrimental to their physical capacities.

\section{Damage to other people}

While the research reviewed above makes clear the broad extent of damage that some students inflict on themselves as a result of their drinking, many consequences of student drinking are simultaneously or specifically inflicted on other people. Residents of local neighborhoods and campus visitors as well as college student, faculty and staff members may suffer as a result of individual students' heavy drinking.

Property damage and vandalism. Damage to neighborhood or residence hall personal space of others and the unsightly residue of intoxication, such as vomit and litter, are common complaints in the aftermath of student parties where alcohol is conspicuous. A consistent $8 \%$ of students admit damaging property or pulling a fire alarm in connection with their drinking during the year in several nationwide surveys conducted throughout the 1990s (Engs and Hanson, 1994; Presley et al., 1996; Wechsler et al., 1998). In Engs et al.'s (1996) national study, 6\% of males and 2\% of females who were "low-risk" in the amount they drank committed property damage in the last year, whereas 33\% of males and $13 \%$ of females who drank at "high-risk" levels did so. Wechsler et al. (1995b) reported 12\% of students claiming to have sustained property damage due to other students' drinking.

Fights and interpersonal violence. The interconnections of alcohol use to aggression and pathological behavior in late adolescent/young adult development in college have been discussed at length elsewhere (see Pezza and Bellotti, 1995; Rivinus and Larimer, 1993). Unfortunately, measures of violence used in studies of college populations frequently combine acts of verbal and physical aggression under the label of fighting even though the former may be more pervasive in college contexts. Nevertheless, $30 \%$ of all students (35\% of drinkers) in the Core Survey nationally reported being involved in an argument or fighting as a result of their drinking or other drug use in the last year (Presley et al., 1996), and 14\% of students (17\% of drinkers) in another national study indicated having gotten into a fight after drinking in the last year (Engs and Hanson, 1994). Although the drinker reporting these incidents presumably experiences this fighting in most instances as a personal negative consequence, others are obviously the target of this aggression and thus experience the negative consequences of this student's intoxication as well, regardless of whether these other people had been drinking too. Indeed, $13 \%$ of students in one national survey stated that, as the result of another student's drinking during the academic year, they had been pushed, hit or assaulted; $22 \%$ stated they had experienced a serious quarrel; and $27 \%$ had been insulted or humiliated (Wechsler et al., 1995b).

Sexual violence. Drinking can also contribute to the violence and damage others experience as victims of sexual aggression. As an intoxicated student's inhibitions against inappropriate behavior are reduced or as one's cognitive ability to accurately perceive messages discouraging sexual advances is dulled, the likelihood of committing rape or some other unwanted sexual contact is significantly increased. Abbey et al. (1998) found that, among men attending a commuter university, greater alcohol consumption increased misperceptions of a woman's sexual intentions, which, in turn, produced a greater likelihood of sexual assault.

Presley et al. (1996) found $10 \%$ of all males $(12 \%$ of male drinkers) and $3 \%$ of all females (4\% of female drinkers) acknowledging that within the last year they had "taken advantage of someone sexually" as a result of their own drinking or other drug use. In another national study, $21 \%$ of students surveyed had experienced an unwanted sexual advance due to another student's drinking within the school year (Wechsler et al., 1995b). For female victims of sexual violence from male acquaintances at a midwestern university ( $27 \%$ of a random sample of female undergraduates), $68 \%$ of their perpetrators were reported to have been drinking - and in the judgment of the victims, almost all of these men were impaired to some degree (Frintner and Rubinson, 1993).

Other potential disturbances. A variety of other disturbances due to heavy drinking and intoxication are frequently noted in news reports and anecdotal accounts of college life, although reliable research on prevalence is slim or nonexistent. Hate-related incidents such as harassment due to one's race, religion or sexual orientation may be more likely to emerge when potential perpetrators are intoxicated, but this phenomenon has not been adequately researched. Noise disruptions generated by student drinking on campus are likely to affect the quality of other students' lives. Nationally, $43 \%$ of students noted they experienced interruptions in study or sleep because of someone's drinking within the academic year, and $44 \%$ reported having had to "babysit" another student who had drunk too much at least once (Wechsler et al., 1995b).

\section{Institutional costs and damage}

Student drinking can also deleteriously affect the institutional well-being of colleges and universities. Property damage reported by students due to drinking (cited above) certainly includes campus property that is vandalized or 
destroyed by intoxicated students in residence halls and public restrooms or at campus concerts and athletic events, much of which will be a cost to the institution as a whole. Accurate research on these consequences is not available, but more than one-quarter of campus administrators surveyed at schools with relatively low drinking levels and more than half of administrators at schools with high drinking levels have reported "moderate" or "major" problems with damage to campus property (Wechsler et al., 1995b).

Given the prevalence of academic impairment previously cited as individual damage to self, one can extrapolate that alcohol misuse may contribute significantly to failure and dropout rates. This becomes an institutional cost as attrition rates and lost tuition revenue increase. The concomitant decrease in actual and perceived academic rigor due to heavy drinking may exact a further cost on the institution because much research suggests that the perceived academic rigor of a school is the most important factor in a student's choice of a school to attend. Strains in "town/gown" relations over student alcohol misuse may add to the institution's "image problem."

Other institutional costs might include added time demands and stress placed on college personnel who are required to deal with student alcohol misuse. Although detailed studies of lost time and emotional tolls are yet to be conducted, it is certainly the case that much of the counseling load in college counseling centers, calls for security staff assistance and administrative hearings on academic and disciplinary cases involve student alcohol misuse. In addition, the time and emotional energy that college administrators must devote to students and families when a student overdoses from drinking and is hospitalized or dies from alcohol poisoning or other alcohol-related incidents can be enormous. Finally, the legal costs of suits brought against academic institutions for liability in these circumstances present another major consequence that goes well beyond the scope of this review.

\section{Patterns of Damage}

\section{Gender differences}

Most research on negative consequences has typically found more total consequences of student drinking for males compared with females (Berkowitz and Perkins, 1987). Explaining gender differences in consequences of drinking is more complicated than simply pointing to commonly observed discrepancies between consumption levels of men and women. Gender differences in amounts consumed do not translate directly into the equivalent differences in intoxication levels because women can typically achieve the same blood alcohol concentration as men while consuming less alcohol due to biological differences in body weight, fat-to-water ratios and metabolic processing. Thus one na- tionwide study of students found that women who drank four drinks in a row were about as likely to experience negative consequences as men who drank five drinks in a row (Wechsler et al., 1995a).

Furthermore, Perkins (1992) has argued that gender differences in overall negative consequences have historically been overestimated based on most research that has not adequately taken into account types of consequences that commonly affect female students who drink. Public risk taking, aggression and deviance are much more culturally ingrained characteristics of the male gender role. Male students do, indeed, exhibit far more problems in public circumstances and in damage caused to other people as a result of their drinking. When damage to self and more private consequences are considered, however, this gender gap diminishes or even disappears. In a random sample of undergraduates at a college in New York, Perkins (1992) found that males were more than three times as likely to have damaged property and twice as likely to have physically injured others during the academic year as a result of drinking when compared with females. In contrast, only slight gender differences were found for the detrimental effect of drinking on poor academic performance and unintended sexual activity in this study, and there was no difference at all when memory loss and injury to self were considered. This pattern can also be found in Wechsler and Isaac's (1992) data from Massachusetts colleges. Men were two to three times as likely to commit property damage, get into fights and get into trouble with police due to drinking, but memory loss, poor academic performance and unplanned sexual activity showed virtually no gender differences when students were grouped by amounts consumed. Similarly, Lo's (1996) surveys of students at a midwestern university and a southern university and Cronin and Ballenger's (1991) study of American students attending college in West Germany revealed sizable gender differences in consequences from drinking when deviant public behavior was involved, but no significant differences in consequences to personal health such as blackouts, vomiting, hangovers, nausea and unintended sexual activity.

\section{Racial and ethnic differences}

Although studies exist showing heavier consumption patterns among white students in comparison with blacks and other racial and ethnic groups (for a review of this literature, see Prendergast, 1994), differences in actual consequences (both in consequences overall and in particular types) have not been equally documented. Data are available on racial/ethnic differences for a range of consequences, however, in the nationwide Core Survey (Presley et al., 1996) database. Native Americans and whites stand out as most problematic on almost all of the 19 items presented. Hispanic students come next in prevalence rates of conse- 
quences matching that of whites on a few items. Asians and blacks exhibit the least problematic rates of consequences across all items. Thus it appears from these data that students' consequence rates from drinking closely follow the racial/ethnic patterns that have been reported in previous literature on consumption levels, regardless of the type of consequence. Moreover, one can adjust for racial/ ethnic differences in abstinence rates by computing the negative consequence rates only for drinkers and still the same overall pattern among groups remains, albeit slightly less pronounced.

\section{Time trends}

Only a few studies document historical patterns in consequence levels over the last generation of college students. A report by Hanson and Engs (1992) provided nationwide data drawn in four comparable samples at 3-year intervals between 1982 and 1991. Significant and consistent decreases across the time period were noted on 3 of the 17 consequence items (where students were asked to note if the consequence had happened at least once in the previous year), all relating to drinking and driving. In contrast, three items showed a significant and consistent increase in consequences: experiencing a hangover, vomiting as a result of drinking and getting into a fight after drinking.

Wechsler et al. (1998) provided a comparison of consequences reported in 1993 and 1997 nationwide surveys of college students. Significantly higher percentages were found in all of the 12 consequence items in 1997, with the rate of increases ranging from $10 \%$ to $50 \%$. This picture of increase in consequences must be tempered somewhat, however, in that absolute differences between time periods ranged from $0.2 \%$ to $4.5 \%$, and statistical significance was easily achieved with these small differences given sample sizes of more than 11,000 in each sample. Furthermore, the percentages experiencing negative consequences here were for drinkers only, but the abstainer rate moved from $16 \%$ in 1993 to $19 \%$ in 1997 (a $22 \%$ increase), so the overall increases in negative consequences would be less for the total population of students.

Finally, Perkins' (1992) study of gender differences in consequences provided data that, although collected in only one undergraduate institution, are based on four representative samples collected across a 10-year period from 1979 to 1989. In six of the eight consequence types considered, there was no evidence of consistent change in the gender patterns. That is, where males were more highly represented on consequences, they tended to remain so across time, and where little or no difference existed between men and women in the earlier years, this remained the case as well. With regard to physical injury to others, however, the very large differences between men and women declined, and with regard to physical injury to self, the gender difference observed in the earlier years disappeared completely by 1989.

\section{Frequency of consequences for individuals}

Only a few studies cited in this review include any information about the frequency with which specific consequences occur for individuals. Presley et al. (1996) recorded six categories of response (never, once, twice, 3 to 5 times, 6 to 9 times and 10 or more times within the year) for consequences. Being hurt or injured, getting in trouble with the police and performing poorly on a test, if experienced at all, occurred only once or twice for most individuals that experienced them. For hangovers, driving a car under the influence and missing class, however, occurrences of 3 to 5 times within the year were just as frequent as reports of only two occurrences. These findings might suggest that although certain drinking outcomes may be viewed as negative by researchers, they may not be perceived or experienced as such by some students.

\section{Developmental and contextual effects}

The prevalence, amount and frequency of alcohol consumption typically increase in the transition from high school to college and typically decrease after graduation. This pattern may be indicative, in part, of developmental transitions from adolescence into early adulthood. Changing social contexts in late adolescence with greater access to alcohol and legal drinking age peers and the nature of the transition into and out of college environments may also play a role. Nationwide data comparing traditional age college students and their noncollege counterparts reveal notably higher rates of heavy episodic drinking (consuming five or more drinks in a row) among the college students (Johnston et al., 1997). This suggests that the culture of heavy alcohol use in peer-intensive campus contexts is a crucial factor for young adults. Analyses examining negative consequences of drinking across transition points are unfortunately very rare, however, and no comparisons of negative consequence rates between college and noncollege young adults were found in the body of research under review here. Nevertheless, a few studies reporting consequence measures across collegiate stages can be cited. Using an index of total negative consequences from drinking, Curtis et al. (1990) found no significant differences between first-year students and seniors at a midsized eastern college (large gender and ethnic differences were revealed on the measure of consequences, however). Presley et al. (1996) uncovered very few differences in rates across the cross-section of undergraduate class years. First-year students were less likely to have experienced a hangover during the year (55\%) compared with seniors $(65 \%)$. First-year students and sophomores were more likely to have gotten 
into trouble with police or campus authorities ( $15 \%$ of each year) in comparison with seniors $(9 \%)$. Driving while intoxicated steadily increased across class years from $28 \%$ to $38 \%$. Being hurt or injured due to drinking during the year steadily declined from $15 \%$ to $11 \%$. Having been taken advantage of sexually steadily declined from $14 \%$ to $10 \%$. Among all the other negative consequences of drinking that were surveyed-poor academic work, missed class, property damage, arguments and fights, nausea and vomiting, memory loss, arrests for driving while intoxicated and suicidal thoughts and attempts - there were no appreciable patterns of difference across class years.

Perkins (1999) examined college to postcollege transitions in drinking behavior and motivations that included measures on a wide range of negative consequences. Graduate cohorts surveyed as undergraduates were again surveyed from 2 to 13 years since graduation about the same negative consequences. This study demonstrated sharp drops in single and multiple negative consequence rates in the first few years after graduation followed by continuing declines in these consequence rates in subsequent postcollegiate years.

\section{Perceptions of self as a problem drinker}

It seems quite reasonable to expect that students who report frequent negative consequences or a consistent pattern of problems resulting from their own drinking during the academic year would also be quite likely to identify themselves as having a drinking problem. Yet in an earlier review of research on problem drinking among college students, Berkowitz and Perkins (1986) pointed out that the literature demonstrated only a modest overlap at best between self-identified prevalence of problem drinking and rates of excessive consumption and negative consequences. The more recent research exploring this notion, albeit very limited, similarly does not provide evidence of a strong connection. For example, in Presley et al. (1996), the negative consequence rate for heavy episodic drinkers was greater than $40 \%$ on nine items ranging from performing poorly on a test $(41 \%)$ to driving while intoxicated $(57 \%)$ to nausea and vomiting (74\%), and yet only $22 \%$ of these high-risk drinkers reported thinking at least once during the year that they might have a drinking or other drug problem. Posavac (1993) asked a small convenience sample of 133 undergraduate students about whether they thought various consequences would be indicative of a person having a drinking problem. Fully two-thirds of the respondents did not think that throwing up at a party due to drinking was indicative of a drinking problem if it only happened once a month. More than half of the students believed that missing classes or appointments after drinking did not constitute a problem if limited to only once a month. In the same study, about half of the males thought becoming sexually aggressive or promiscuous, getting into a fight or being unable to remember what happened after drinking, likewise, was not indicative of a drinking problem if limited to once a month. Furthermore, one-third of all respondents did not judge throwing up at a party due to drinking as indicative of a problem even if it happened more than once a month.

\section{Need for Further Research in Academic Institutions}

Although many studies on negative consequences of student drinking have been published, systematic assessment is far from complete. For example, the topics of impaired athletic performance and the cost of lost educational opportunities due to drinking have not been thoroughly assessed. There is little published on the clustering of consequences by type of consequence or among subgroups of students. Also, the negative consequence of increased risk of alcohol dependence in later life due to heavy college drinking is an important potential consequence to consider. Conducting empirical studies of this type of consequence is very difficult, however, given the need for longitudinal panel data over a significant period of time. Thus long-term consequences of college drinking remain largely speculative.

The need for longitudinal data goes beyond the desire to study long-term effects. Much of the current data linking the degree of problem behavior to reports about one's usual level of alcohol consumption are correlational studies. In this research, it is not at all clear whether some problem behaviors are a product of the drinking lifestyle of students or simply a covariate where both drinking and the problem behavior reflect other influences in one's social background. Current research on the association between grade point average and drinking presents an important example of this dilemma.

Alcohol-related highway crashes most certainly produce consequences for persons other than the drinking driver in many instances. Given the level of impaired driving noted by students in research cited earlier, it is likely that significant harm to self and others may result.

There can be little doubt that the cumulative individual damage to self and others as cited in this review produces a substantial demand on the resources of institutions where student alcohol misuse is relatively pervasive. Extra time required in police work, counseling, hospital services, custodial services and legal counsel, as well as in administrative "damage control" in public relations, seems apparent.

In short, an extensive accumulation of research on college drinking has led to a much clearer picture of the problems produced by student alcohol misuse. Yet more research on variation and concentration of consequences within college populations, longitudinal studies of student developmental behavior and studies of student perspectives on what 
are experienced as negative consequences are all needed to portray more accurately the actual and perceptual landscape of drinking consequences in college.

\section{Research Implications for Prevention}

Although the picture is not complete, researchers surveying heavy drinking in college populations have demonstrated a wide range of negative consequences that personally affect the drinkers themselves, others with whom they come in contact and the institutions they attend. The prevalence rates for most negative effects on oneself and negative effects on others show that, for most of these consequences, at least $10 \%$ of students and frequently as much as one-third of the population are negatively affected in a given year. Moreover, there is no evidence that prevalence rates for most consequences are declining nationally. Thus the problems generated by student misuse of alcohol continue to present a major health hazard and social problem for higher education communities and for society at large.

Amid this assessment it is also important, however, to emphasize that these consequences are not occurring for the majority of students in most contexts and that this review should not be interpreted as an indictment against students in general. When the majority of students are misperceived among peers as more problematic than is the case and when students and staff think the majority of students carelessly let drinking hurt themselves and othersmisperceptions of the norms that widely occur in most college populations (Perkins et al., 1999) - then these misperceptions will facilitate or give social license to the students who are problematic and destructive in the misuse of alcohol (Perkins 1997; Perkins and Berkowitz, 1986; Perkins and Wechsler, 1996). Thus prevention planners must simultaneously keep in mind and publicly promote to students the fact that the majority of students are typically not problematic with regard to drinking.

Furthermore, the effectiveness of traditional prevention strategies that simply rely on warnings about harm to oneself must be questioned when used in attempts to reduce types of consequences found to be relatively pervasive in student populations and for types of consequences that are just as likely to occur multiple times as to occur only once for the individual during the academic year. These findings suggest that such consequences may not be experienced or perceived as particularly negative by students reporting them even though academic staff and prevention specialists may view the consequences as negative. Otherwise, frequent or repeated occurrence of particular consequences would be discouraged once students had experienced the consequence. Indeed, there is only a modest overlap between selfidentified problem drinking and the incidence of objectively defined negative consequences. Thus simply making students more aware of drinking hazards that they do not per- ceive or subjectively experience as indicative of a problem, or simply attempting to scare students with reports of problem rates, is not likely to be an effective prevention approach.

Thinking that consequences to oneself will "teach a lesson" must be questioned, not only by the fact that multiple instances of some drinking consequences occur during the academic year for a significant minority of students, but also by the fact that, for most types of consequences, the evidence does not suggest a notable decline in rates from one year to the next as students progress through the college years. An intoxicated student who behaves obnoxiously in public may feel no embarrassment or condemnation at all if the student's peers complacently ignore him or her or if both this student and the student's peers simply think of the student's actions as typical of most students. A student who vomits during participation in a drinking game may experience the physical discomfort as only a relatively minor negative side effect of his or her drinking when weighed against his or her erroneous notion that this type of activity is common among almost all students and his or her actual experience of immediate peer approval in the cheers of other participants.

Furthermore, many consequences identified in this review do not directly affect the student who produces them. Indeed, the lists of consequences to others and to institutions from students' drinking are equally problematic, and these consequences often occur without any immediate negative result for the student who is misusing alcohol. Thus prevention approaches are needed that enlist faculty, staff and, most importantly, the majority of students in reacting negatively and in a clear and direct fashion to students who do misuse alcohol and in communicating not only the acceptability but also the normality of healthy student behavior, so that negative consequences of drinking are not inadvertently enabled or rewarded in academic communities. The extensive and tragic list of consequences due to persistent student alcohol misuse makes clear the stake all higher education community members have in conveying this message.

\section{References}

AbBey, A. Acquaintance rape and alcohol consumption on college campuses: How are they linked? J. Amer. Coll. Hlth 39: 165-169, 1991.

Abbey, A., McAuslan, P. And Ross, L.T. Sexual assault perpetuation by college men: The role of alcohol, misperception of sexual intent, and sexual beliefs and experiences. J. Social Clin. Psychol. 17: 167-195, 1998.

Abbey, A., Ross, L.T., McDuffie, D. and McAuslan, P. Alcohol and dating risk factors for sexual assault among college women. Psychol. Women Q. 20: 147-169, 1996.

Anderson, P.B. And Mathieu, D.A. College students' high-risk sexual behavior following alcohol consumption. J. Sex Marital Ther. 22: 259$264,1996$. 
Berkowitz, A.D. And Perkins, H.W. Problem drinking among college students: A review of recent research. J. Amer. Coll. Hlth 35: 21-28, 1986.

Berkowitz, A.D. and Perkins, H.W. Recent research on gender differences in collegiate alcohol use. J. Amer. Coll. Hlth 36: 123-129, 1987.

Buelow, G. And Koeppel, J. Psychological consequences of alcohol induced blackout among college students. J. Alcohol Drug Educ. 40 (3): 10-20, 1995

Cronin, C.J. AND BaLlenger, R.G. Alcohol use and negative consequences among American college students in West Germany. Int. J. Addict. 26: 1123-1136, 1991.

Curtis, K., Genaro, S., Roberts, A. and Kayson, W.A. Effects of sex, race, and year in college on self-reported drinking-related problem behaviors. Psychol. Rep. 66 (3, pt 1): 871-874, 1990.

Desiderato, L.L. and Crawford, H.J. Risky sexual behavior in college students: Relationships between number of sexual partners, disclosure of previous risky behavior, and alcohol use. J. Youth Adolesc. 24: 5568, 1995.

Engs, R.C. And Aldo-Benson, M. The association of alcohol consumption with self-reported illness in university students. Psychol. Rep. 76 (3, pt 1): 727-736, 1995.

Engs, R.C., Diebold, B.A. and Hanson , D.J. The drinking patterns and problems of a national sample of college students, 1994. J. Alcohol Drug Educ. 41 (3): 13-33, 1996.

Engs, R.C. And Hanson, D.J. Boozing and brawling on campus: A national study of violent problems associated with drinking over the past decade. J. Crim. Justice 22: 171-180, 1994.

Frintner, M.P. AND Rubinson, L. Acquaintance rape: The influence of alcohol, fraternity membership, and sports team membership. J. Sex Educ. Ther. 19: 272-284, 1993.

Gross, W.C. and Billingham, R.E. Alcohol consumption and sexual victimization among college women. Psychol. Rep. 82: 80-82, 1998.

Hanson, D.J. And Engs, R.C. College students' drinking problems: A national study, 1982-1991. Psychol. Rep. 71: 39-42, 1992.

HARRINGTON, N.T. AND LeITENBERG, H. Relationship between alcohol consumption and victim behaviors immediately preceding sexual aggression by an acquaintance. Viol. Victims 9: 315-324, 1994.

Johnston, L.D., O’Malley, P.M. and Bachman, J.G. National Survey Results on Drug Use from the Monitoring the Future Study, 1975-1995, Vol. 2, NIH Publication No. 98-4140, Washington: Government Printing Office, 1997.

Koss, M.P., Gidycz, C.A. And Wisniewski, N. The scope of rape: Incidence and prevalence of sexual aggression and victimization in a national sample of higher education students. J. Cons. Clin. Psychol. 55: 162-170, 1987.

Leichliter, J.S., Meilman, P.W., Presley, C.A. and Cashin, J.R. Alcohol use and related consequences among students with varying levels of involvement in college athletics. J. Amer. Coll. Hlth 46: 257-267, 1998.

Lo, C.C. Are women heavier drinkers than we thought they were? J. Stud. Alcohol 57: 531-535, 1996.

Meilman, P.W. Alcohol-induced sexual behavior on campus. J. Amer. Coll. Hlth 42: 27-31, 1993.

Meilman, P.W., Stone, J.E., Gaylor, M.S. and Turco, J.H. Alcohol consumption by college undergraduates: Current use and 10-year trends. J. Stud. Alcohol 51: 389-395, 1990.

Perkins, H.W. Gender patterns in consequences of collegiate alcohol abuse: A 10-year study of trends in an undergraduate population. J. Stud. Alcohol 53: 458-462, 1992.
Perkins, H.W. College student misperceptions of alcohol and other drug norms among peers: Exploring causes, consequences, and implication for prevention programs. In: Designing Alcohol and Other Drug Prevention Programs in Higher Education, Newton, MA: Higher Education Center for Alcohol and Other Drug Prevention, Department of Education, 1997, pp. 177-206.

Perkins, H.W. Stress-motivated drinking in collegiate and postcollegiate young adulthood: Life course and gender patterns. J. Stud. Alcohol 60: 219-227, 1999.

Perkins, H.W. and Berkowitz, A.D. Perceiving the community norms of alcohol use among students: Some research implications for campus alcohol education programming. Int. J. Addict. 21: 961-976, 1986.

Perkins, H.W., Meilman, P.W., Leichliter, J.S., Cashin, J.R. and Presley, C.A. Misperceptions of the norms for the frequency of alcohol and other drug use on college campuses. J. Amer. Coll. Hlth 47: 253-258, 1999.

Perkins, H.W. and Wechsler, H. Variation in perceived college drinking norms and its impact on alcohol abuse: A nationwide study. J. Drug Issues 26: 961-974, 1996.

Pezza, P.E. and Bellotti, A. College campus violence: Origins, impacts, and responses. Educ. Psychol. Rev. 7: 105-123, 1995.

Posavac, E.J. College students' views of excessive drinking and the university's role. J. Drug Educ. 23: 237-245, 1993.

Poulson, R.L., Eppler, M.A., Satterwhite, T.N., Wuensch, K.L. and Bass, L.A. Alcohol consumption, strength of religious beliefs, and risky sexual behavior in college students. J. Amer. Coll. Hlth 46: 227-232, 1998.

Prendergast, M.L. Substance use and abuse among college students: A review of recent literature. J. Amer. Coll. Hlth 43: 99-113, 1994.

Presley, C.A., Meilman, P.W. and Cashin, J.R. Alcohol and Drugs on American College Campuses: Use, Consequences and Perceptions of the Campus Environment, Volume IV: 1992-1994, Carbondale, IL: Core Institute, Southern Illinois University, 1996.

Rivinus, T.M. and Larimer, M.E. Violence, alcohol, other drugs, and the college student. J. Coll. Student Psychother. 8 (1-2): 71-119, 1993.

Sarvela, P.D., Taylor, E.L., Drolet, J.C. and Newcomb, P.R. Indicators of drinking and driving among university students. J. Hlth Educ. 19 (5): 72-77, 1988.

Wechsler, H., Dowdall, G.W., Davenport, A. and Rimm, E.B. A genderspecific measure of binge drinking among college students. Amer. J. Publ. Hlth 85: 982-985, 1995a.

Wechsler, H., Dowdall, G.W., Maenner, G., Gledhill-Hoyt, J. and Lee, $\mathrm{H}$. Changes in binge drinking and related problems among American college students between 1993 and 1997. Results of the Harvard School of Public Health College Alcohol Survey. J. Amer. Coll. Hlth 47: 5768, 1998.

Wechsler, H. and IsaAc, N. "Binge" drinkers at Massachusetts colleges: Prevalence, drinking style, time trends, and associated problems. JAMA 267: 2929-2931, 1992.

Wechsler, H., Moeykens, B., Davenport, A., Castillo, S. and Hansen, J. The adverse impact of heavy episodic drinkers on other college students. J. Stud. Alcohol 56: 628-634, 1995 b.

Werch, C.E., GoRman, D.R. And Marty, P.J. Relationship between alcohol consumption and alcohol problems in young adults. J. Drug Educ. 17: 261-275, 1987.

Werner, M.J., Walker, L.S. and Greene, J.W. Alcohol expectancies, problem drinking, and adverse health consequences. J. Adolesc. Hlth 14: 446-452, 1993.

Wood, P.K., Sher, K.J., Erickson, D.J. and DeBord, K.A. Predicting academic problems in college from freshman alcohol involvement. J. Stud. Alcohol 58: 200-210, 1997. 